Please reffer to:

Virág Zoltán;Jármai Károly: Optimum design of transportation tube elements

in: Jármai Károly;Farkas József

Design, Fabrication and Economy of Metal Structures: International Conference

Proceedings. $671 \mathrm{p}$.

Konferencia helye, ideje: Miskolc, Magyarország, 2013.04.24-2013.04.26. Berlin;

Heidelberg: Berlin, Springer, 2013. pp. 85-90.

(ISBN:978-3-642-36690-1)

\title{
Optimum Design of Transportation Tube Elements
}

\author{
Z. Virág and K. Jármai \\ University of Miskolc, Miskolc, Hungary \\ \{gtbvir, altjar\}@uni-miskolc.hu
}

\begin{abstract}
Transportation tubes have important rule in the oil and gas industry. Using different steel grades and different geometrical and loading conditions we can determine the optimum sizes. The optimization can consider both material and fabrication costs. The optimum design is made using an iterative technique. The constraints are from the inner pressure and deadload the stress and stability ones. The spanlength of the tube varies and has an important role in the optimization. The deflection of the tube is proportional to the spanlength and if its limit is small it increases the optimum sizes of the tube. Another constraint is the transfer capacity. The paper shows a parametric study on these conditions.
\end{abstract}

Keywords: tube element, $\mathrm{CO}_{2}$ transportation, stress, stability, slenderness, optimum design.

\section{Introduction}

In the past centuries, fossil fuels have increased green house gases concentration in the atmosphere, with effects on low layer heating and global climate condition changes. Under Kyoto Protocol's directives, many methods for emissions reduction, with limited impact on the economies of the countries that have accepted this document, have been studying: particularly the reduction of $\mathrm{CO}_{2}$ emission. Carbon Capture and Storage (CCS) technologies, still in test and study phase, consist in a series of procedures to capture $\mathrm{CO}_{2}$ from industrial flue gases and to store it into appropriate sites to avoid its atmosphere dispersion.

After capture, carbon dioxide must be transported to the storage site. $\mathrm{CO}_{2}$ is an inert gas and can be easily handled and transported in high pressure pipelines. Alternatively it can be transported in industrial tanks by ship, rail and truck. The risks of pipelines leakage are very small, as it is demonstrated by the long time utilization of oil and gas pipelines, but to minimize any risks, $\mathrm{CO}_{2}$ pipelines could be routed away from large centres of population to avoid danger caused from $\mathrm{CO}_{2}$ toxicity. Pipelines can be considered the most suitable method for transporting $\mathrm{CO}_{2}$, since the cost for this technology depends mainly on the distance, the quantity transported and whether the pipelines are onshore or offshore (Bumb et al. 2009).

Requirements for $\mathrm{CO}_{2}$ pipeline quality specifications are subjects of debate. To date, most existing compositional specifications appear only within private contracts between buyers and sellers. As a result, there is little publicly available information on the quality specifications of $\mathrm{CO}_{2}$ pipelines. However, uniform $\mathrm{CO}_{2}$ quality specifications may be useful to promote development of a national $\mathrm{CO}_{2}$ pipeline network. While imposing a national uniform quality specification on $\mathrm{CO}_{2}$ composition in 
pipelines can be expensive to a given plant in terms of both capital investments and operating costs, such uniform quality specifications may be necessary to promote a national $\mathrm{CO}_{2}$ pipeline infrastructure. Recognition today of what might be an appropriate national compositional specification would prove invaluable in the early stages of source and pipeline design.

A typical $\mathrm{CO}_{2}$ process chain is shown in Fig. 1. (IZ Klima e. V., 2009).

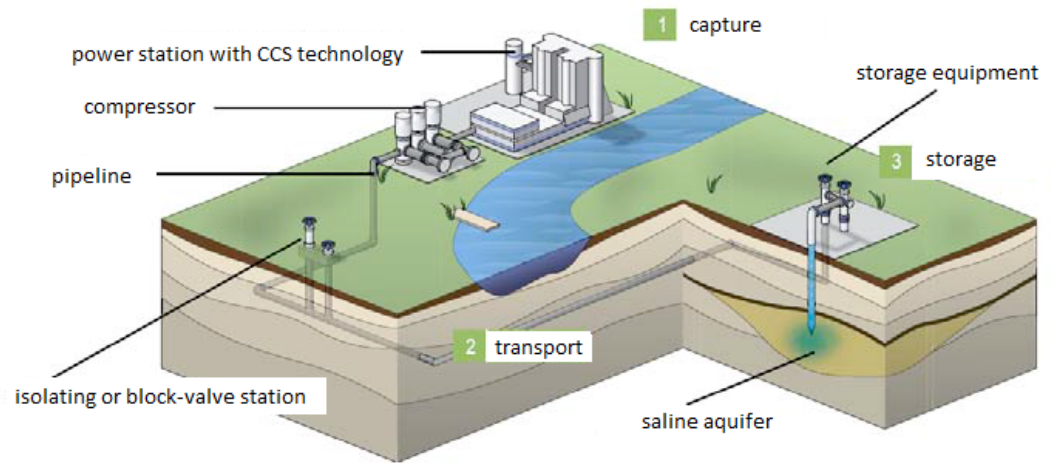

Fig. 1. CCS technology

$\mathrm{CO}_{2}$ pipelines are similar in many respects in design and operation to natural gas pipelines; however, because the $\mathrm{CO}_{2}$ is normally transported as a supercritical fluid, there are a number of significant differences. To maintain the product in its supercritical state, it is transported at pressures that range from 80 to 180 bar. These pressures are higher than the operating pressures used in most natural gas pipelines, which typically range from 10 to 100 bar. Booster stations along the pipeline route maintain the necessary pipeline pressure for $\mathrm{CO}_{2}$ pipelines. Because the supercritical $\mathrm{CO}_{2}$ behaves as a liquid in the pipeline, pumps, rather than compressors, are used at $\mathrm{CO}_{2}$ pipeline booster stations. The increased pressure in $\mathrm{CO}_{2}$ pipelines is typically accommodated with thicker-walled pipe than that used for natural gas transportation (Amann et al. 2010).

In this paper above-ground pipelines are investigated.

\section{Design Constraints}

In this kind of design for above-ground high pressure pipeline transportation we have to calculate with three kinds of constraints. These are stress, deflection and stability constraints.

\subsection{Stress Constraint}

We can calculate the stress constraint as follows,

The distributed load is

$$
p=\left(1,2 A \rho_{a}+1,1 A_{c s o} \rho_{g}\right) g
$$


where $A$ is the area of the tube, $\rho_{a}$ is the density of the steel, $A_{c s o}$ is the area of transportation, $\rho_{g}$ is the density of high pressure gas.

In structural analysis Clapeyron`s theorem of three moments is a relationship among the bending moments at three consecutive supports of a horizontal beam.

Let $A, B, C$ be the three consecutive points of support, and denote by $l$ the length of $A B$ by $l$ the length of $B C$, by $w$ and w` the weight per unit of length in these segments. Then the bending moments $M_{\mathrm{A}}, M_{\mathrm{B}}, M_{\mathrm{C}}$ at the three points are related by

$$
M_{A} l+2 M_{B}(l+l)+M_{C} l=\frac{6 a_{1} x_{1}}{l}+\frac{6 a_{2} x_{2}}{l}
$$

where $a_{1}$ is the area on the bending moment diagram due to vertical loads on $\mathrm{AB}, a_{2}$ is the area due to loads on $\mathrm{BC}, x_{1}$ is the distance from $\mathrm{A}$ to the center of gravity for the bending moment diagram for $\mathrm{AB}, x_{2}$ is the distance from $\mathrm{C}$ to the center of gravity for the bending moment diagram for $\mathrm{BC}$.

So the bending moment at middle support according to the Clapeyron formula

$$
M_{2}=\frac{2,5 p L^{2}}{4}
$$

where $L$ is the distance between the supports.

Stress

$$
\sigma_{1}=\frac{M_{2}}{K_{x}}
$$

where

$$
K_{x}=\frac{\left(D^{4}-d^{4}\right) \pi}{32 D}
$$

where $D$ is the outside diameter and $d$ is the inside diameter.

The chamber formula

$$
\sigma_{2}=\frac{p_{b} d}{2 t}
$$

where $p_{b}$ is the inner pressure, $t$ is the wall thickness.

Reduced stress

$$
\sigma_{R}=\sqrt{\sigma_{1}^{2}+\sigma_{2}^{2}-\sigma_{2} \sigma_{2}}
$$

The permissible stress is

$$
R_{a d m}=\frac{f_{y}}{n_{e}}
$$

where $n_{e}$ safety factor is 1,2 and $f_{y}$ is the yield stress.

The stress constraint is

$$
\sigma_{R} \leq R_{a d m}
$$




\subsection{Deflection Constraint}

The deflection of the pipe between the supporters

$$
w=\frac{p L^{4}}{284 E I_{x}}
$$

where $E$ is the elastic modulus and the moment of inertia is

$$
I_{x}=\frac{\left(D^{4}-d^{4}\right) \pi}{64}
$$

The limitation of the deflection is

$$
w \leq \frac{L}{300}
$$

\subsection{Stability Constraint}

This constraint depends on the ratio between the outer diameter and the wall thickness.

$$
\frac{D}{t} \leq 90 \varepsilon^{2}
$$

where

$$
\varepsilon=\sqrt{\frac{235 \mathrm{MPa}}{f_{y}}}
$$

\section{$3 \quad$ Numerical Results}

The aim of this investigation is to find the lowest mass per unit length pipe for a given volume flow rate. To get this optimum, we have to find the best outside diameter and wall thickness combination due to the European Standard EN 10220:2002) which fulfil the three design constraints. In our numerical example the volume flow rate is $82 \mathrm{~m}^{3} / \mathrm{s}$ like it is used in Weyburn pipeline (IPCC 2005). We vary the distance between the supporters $(L=20,25$ and $30 \mathrm{~m})$ and the yield stress of the material of the tube $\left(f_{y}=355\right.$ and $\left.448 \mathrm{MPa}\right)$. The optimum results are marked with italics.

Table 1. Results for $L=20 \mathrm{~m} f_{y}=448 \mathrm{MPa}$

\begin{tabular}{ccc}
$\begin{array}{c}\text { outside } \\
\text { diameter } \\
{[\mathrm{mm}]}\end{array}$ & $\begin{array}{c}\text { wall } \\
\text { thickness } \\
{[\mathrm{mm}]}\end{array}$ & $\begin{array}{c}\text { mass per } \\
\text { unit length } \\
{[\mathrm{kg} / \mathrm{m}]}\end{array}$ \\
\hline 508 & 12,5 & 153 \\
457 & 12,5 & 137 \\
406,4 & 14,2 & 137 \\
355,6 & 14,2 & 120 \\
323,9 & 16 & 121 \\
\hline
\end{tabular}

Table 2. Results for $L=20 \mathrm{~m} f_{y}=355 \mathrm{MPa}$

\begin{tabular}{ccc}
$\begin{array}{c}\text { outside } \\
\text { diameter } \\
{[\mathrm{mm}]}\end{array}$ & $\begin{array}{c}\text { wall } \\
\text { thickness } \\
{[\mathrm{mm}]}\end{array}$ & $\begin{array}{c}\text { mass per } \\
\text { unit length } \\
{[\mathrm{kg} / \mathrm{m}]}\end{array}$ \\
\hline 610 & 12,5 & 184 \\
508 & 14,2 & 173 \\
457 & 14,2 & 155 \\
406,4 & 16 & 154 \\
355,6 & 20 & 166 \\
\hline
\end{tabular}


Table 3. Results for $L=25 \mathrm{~m} f_{y}=448 \mathrm{MPa}$

\begin{tabular}{ccc}
\hline $\begin{array}{c}\text { outside } \\
\text { diameter } \\
{[\mathrm{mm}]}\end{array}$ & $\begin{array}{c}\text { wall } \\
\text { thickness } \\
{[\mathrm{mm}]}\end{array}$ & $\begin{array}{c}\text { mass per } \\
\text { unit length } \\
{[\mathrm{kg} / \mathrm{m}]}\end{array}$ \\
\hline 762 & 17,5 & 321 \\
711 & 16 & 274 \\
610 & 14,2 & 209 \\
508 & 14,2 & 173 \\
457 & 16 & 174 \\
\hline
\end{tabular}

Table 5. Results for $L=30 \mathrm{~m} f_{y}=448 \mathrm{MPa}$

\begin{tabular}{ccc}
\hline $\begin{array}{c}\text { outside } \\
\text { diameter } \\
{[\mathrm{mm}]}\end{array}$ & $\begin{array}{c}\text { wall } \\
\text { thickness } \\
{[\mathrm{mm}]}\end{array}$ & $\begin{array}{c}\text { mass per } \\
\text { unit length } \\
{[\mathrm{kg} / \mathrm{m}]}\end{array}$ \\
\hline 914 & 20 & 441 \\
813 & 17,5 & 343 \\
762 & 17,5 & 321 \\
711 & 16 & 274 \\
610 & 16 & 234 \\
\hline
\end{tabular}

Table 4. Results for $L=25 \mathrm{~m} f_{y}=355 \mathrm{MPa}$

\begin{tabular}{ccc}
\hline $\begin{array}{c}\text { outside } \\
\text { diameter } \\
{[\mathrm{mm}]}\end{array}$ & $\begin{array}{c}\text { wall } \\
\text { thickness } \\
{[\mathrm{mm}]}\end{array}$ & $\begin{array}{c}\text { mass per } \\
\text { unit length } \\
{[\mathrm{kg} / \mathrm{m}]}\end{array}$ \\
\hline 914 & 16 & 354 \\
813 & 14,2 & 280 \\
762 & 14,2 & 262 \\
711 & 12,5 & 215 \\
610 & 14,2 & 209 \\
\hline
\end{tabular}

Table 6. Results for $L=30 \mathrm{~m} f_{y}=355 \mathrm{MPa}$

\begin{tabular}{ccc}
\hline $\begin{array}{c}\text { outside } \\
\text { diameter } \\
{[\mathrm{mm}]}\end{array}$ & $\begin{array}{c}\text { wall } \\
\text { thickness } \\
{[\mathrm{mm}]}\end{array}$ & $\begin{array}{c}\text { mass per } \\
\text { unit length } \\
{[\mathrm{kg} / \mathrm{m}]}\end{array}$ \\
\hline 1067 & 20 & 516 \\
1016 & 17,5 & 431 \\
914 & 16 & 354 \\
813 & 14,2 & 280 \\
762 & 14,2 & 262 \\
\hline
\end{tabular}

\section{Conclusion}

The paper deals with the calculation of steel pipeline for high pressure $\mathrm{CO}_{2}$ transport. We can determine the optimum sizes of the pipe (diameter and thickness) to reduce the weight and the cost of the transport system. If the outside diameter is high one cannot reduce the wall thickness because the stability constraint becomes active. If it is small the stress constraint becomes active.

Acknowledgements. The research was supported by the Hungarian Scientific Research Fund OTKA T 75678 and by the TÁMOP 4.2.1.B-10/2/KONV-2010-0001 entitled "Increasing the quality of higher education through the development of research - development and innovation program at the University of Miskolc supported by the European Union, co-financed by the European Social Fund."

\section{References}

Amann, R., et al.: A Policy, Legal, and Regulatory Evaluation of the Feasibility of a National Pipeline Infrastructure for the Transport and Storage of Carbon Dioxide. Topical Report, 102 p. (2010)

Bumb, P., Desideri, U., Quattrocchi, F., Arcioni, L.: Cost Optimized $\mathrm{CO}_{2}$ Pipeline Transportation Grid: A case Study from Italian Industries. World Academy of Science, Engineering and Technology 58, 138-145 (2009) 
European Standard EN 10220:2002

Davidson, O., de Coninck, H.C., Loos, M., Meyer, L.A. (eds.): IPCC, IPCC Special Report on Carbon Dioxide Capture and Storage, 442 p. Cambridge University Press, Cambridge (2005)

IZ-Klima e. V., CCS Transport von $\mathrm{CO}_{2}$ : Pipelines für den Klimaschutz. Information Brochure (2009), http: //www.izk_broschuere_transport_2.aufl_web.pdf 